\title{
Numerical study of mixed convection inside a three-dimensional ventilated cavity in the presence of an isothermal heating block
}

\author{
Hicham Doghmi*, Btissam Abourida, Lahoucin Belarche, Mohamed Sannad, Meriem Ouzaouit \\ National School of Applied Sciences, Ibn Zohr University, laboratory of mechanics, energy and environment(LMPEE) B.P \\ 1136 Agadir, 80000, Morocco
}

Corresponding Author Email: hicham.gte@gmail.com

https://doi.org/10.18280/ijht.360209

Received:4 October 2017

Accepted: 20 April 2018

\section{Keywords:}

mixed convection, ventilated cavity, heated block, three-dimensional, numerical study

\begin{abstract}
A numerical investigation has been carried out to analyze the mixed convection heat transfer in isothermal heating source within three-dimensional ventilated cavity with different inletoutlet locations by using finite volume method. The results are presented in terms of flow structures, temperature distribution, and average Nusselt number for various combinations of thermal controlling parameters, namely, Reynolds number $(50 \leq \mathrm{Re} \leq 100)$ and Richardson number $(0 \leq \mathrm{Ri} \leq 10)$. The obtained results show that the flow intensity and the heat transfer rate can be significantly improved by an optimal choice of the mentioned parameters for different inlet-outlet locations.
\end{abstract}

\section{INTRODUCTION}

In the last few decades, mixed convection in ventilated cavities has been the subject of extensive research, due to its wide applicability in electronic equipment, air-cooling process, thermal design of buildings, nuclear reactors and others Mixed convection is the most simple and low-cost mode of cooling operation. This practical interest explains the existence of various studies considering different configurations and boundary conditions. Hence, the case of partially heating surface was investigated numerically by many authors, such as Papanicolaou and Jaluria [1-2] who studied the mixed convection provided from a heated source in a two-dimensional cavity. The obtained results show that heat transfer rate increase by increasing the solid wall thermal conductivity. In addition, the cooling rate was found to be higher when the outlet flow opening was located near the bottom of the vertical wall.

Hsu et al. [3] presented a numerical study of mixed convection inside a two-dimensional ventilated cavity with partially heated wall. They also concluded that the higher heat transfer rate dissipated from the source is maximum when the outflow opening is positioned in the lower part of the vertical wall.

Manca et al. [4] numerically studied the mixed convective flow over a partially open cavity. Their principal results showed that the maximum dimensional temperature increase as the Reynolds and the Richardson numbers are increased, and the highest thermal performance was achieved in the case of opposing forced flow configuration. Later, a similar problem was investigated experimentally by Manca et al. [5]. They found, that the surface temperature for $\mathrm{Re}=100$ was lower compared to the one corresponding to $\mathrm{Re}=1000$.

The case of totally heating surface was considered in a series of papers presented by Raji et al. [6-8] who studied numerically the mixed convection heated transfer in ventilated cavities with uniform heat flux. The results show that the highest heat transfer performance was achieved for the BT configuration where the air injection is from the bottom. Different flow regimes regions were delineated in the $\mathrm{Ra}-\mathrm{Re}$ plane. Similar investigations were also carried out taking into account the effect of the thermal radiation on mixed convection [9-12]. Saha et al. [13] conducted a numerical study of the combined natural and forced convection in a two-dimonsional enclosure with a uniform heat flux. They found that the increase of the thermal parameters ( $\mathrm{Gr}$ and $\mathrm{Re}$ ) and the effects of different ventilation orientations could lead to the best cooling effectiveness.

Messaoud et al. [14] presented a numerical study of mixed convection in various acrossshape concave cavities They reported that the triangular alveolus highlights a higher heat transfer rate for higher Re numbers.

Omri and Nasrallah [15] compared numerically the mixed convection in an air-cooled cavity for two different the inletoutlet openings positions. They concluded that the maximum cooling effectiveness is achieved when the inlet and the outlet openings are, respectively, located near the bottom of the hot wall and the top of the cold wall.

Later on, Singh and Sharif [16] extended their works by considering six placements of the air inlet and exit configurations deferentially heated. The higher cooling efficiency and the higher average Nusselt number are achieved when the air is injected from the bottom of the cold wall and exit from the top of the hot wall.

The adding of obstacles inside the cavity was also used as a way to control the fluid flow and heat transfer. Hence, Rahman et al. [17] performed a numerical investigation of the effects of Reynolds and Prandtl numbers on mixed convection in a two-dimensional square cavity with a heatgenerating solid circular obstacle. They found that the heat transfer rate increase with the increasing of the thermal parameters ( $\mathrm{Re}, \mathrm{Pr}$ ) for different values of Ri. A similar investigation with different thermal conditions on the cavity 
walls was studied by Gupta et al. [18]. They found that the average Nusselt number increases with increasing the cylinder diameter and decreases for higher Ri.

Bhoite et al. [19] conducted a numerical investigation of mixed convection flow in a shallow cavity with a series of heat-generating components and ceiling extraction openings. They reported that the block surface temperature decreases with the Reynolds number for Grashof numbers less than or equal to $5.10^{5}$

Rahman et al. [20] studied numerically the mixed convection in a two-dimensional ventilated cavity in the presence of a heat-generating square block. They indicated that the block size affects strongly the streamline distribution in the cavity and the average Nusselt numbers increases with increasing Ri for different locations of the solid block.

Shuja et al. [21] analyzed numerically the fluid flow around solid blocks in a rectangular cavity differentially heated. They found that the orientation and the size of the blocks created a complex flow structure inside the cavity.

We have to notice that all the previous considered works are based on a two dimensional analysis. However, the three dimensional case was investigated by some authors such as Stiriba et al. [22] who studied numerically the mixed convection in a three-dimensional open enclosure. Their Results showed that at moderate Grashof numbers, the flow becomes stable, while it becomes unsteady with KelvinHelmholtz instabilities at the shear layer. In addition, the heat transfer rate increases For $\mathrm{Re}=1000$ and $\mathrm{Gr}=107$.

Moraga and López [23] compared numerically the mixed convection in a two and three-dimensional air-cooled cavity. They observed a major difference between the global Nusselt numbers calculated from the 2-D and the 3-D models. In fact, the 3-D model was needed to capture the fluid mechanics for $\mathrm{Ri}=10$ when $10 \leq \operatorname{Re} \leq 250$, and to calculate the global Nusselt number when $\mathrm{Re}=500$ for $\mathrm{Ri}<1$.

A recent $3 \mathrm{D}$ numerical investigation of the inlet opening size effect on the mixed convection inside a threedimensional ventilated cavity was presented by Doghmi et al. [24] They concluded that the average Nusselt number at the active walls increases with increasing Richardson numbers, and the heat transfer rate increase and decrease at the hot and cold wall respectively by increasing the inlet opening section.

The case of cavities with obstacles has also been presented by some authors. Hence, mixed convection in a threedimensional open cavity with a vertical heat source was studied by Rajesh Kanna et al. [25] Their results show that at higher Reynolds number and higher aspect ratios, the heat transfer in the right surface of the isothermal block becomes greater than the others.

Fontana et al. [26] studied numerically the threedimensional mixed convection in partially opened cavities with internal heat sources. Their results indicated the existence of two different processes controlling the formation of recirculation inside the cavity; hydrodynamic recirculation and thermal recirculation. In addition, they showed a strong three-dimensional nature of the flow inside the cavity, indicating that a simplified two-dimensional model is not able to capture some important aspects of the system behavior.

Hence, the literature review showed the existence of a limited number of three-dimensional studies and that explains the choice of our present physical model. The purpose of our study is to compare numerically the effects of conjugated Richardson numbers and Reynolds numbers on the thermal transport and fluid flow phenomena in the considered tridimensional enclosures.

\section{PHYSICAL PROBLEM AND GOVERNING EQUATIONS}

The studied configurations are presented in (Fig. 1). The first configuration (Fig. 1a) consists of a three-dimensional ventilated cavity, which has an inlet opening with a rectangular cross section of relative height $\mathrm{B}=\mathrm{h} / \mathrm{H}$ located on the top of the left vertical wall, allowing the air flow to get in at a uniform velocity $U_{i}$ and ambient temperature $T_{C}$. Whereas the flow leaves via the outlet opening which has the same relative height $\mathrm{B}=\mathrm{h} / \mathrm{L}$ as the entrance one. This opening is placed at the bottom of the opposite vertical wall. This configuration will be called as TB configuration (Fig 1a). Inversely, when the air injection is from the bottom of the right vertical wall and the outlet located on the top of the opposite wall, the configuration will be called as BT configuration (Fig. 1b)
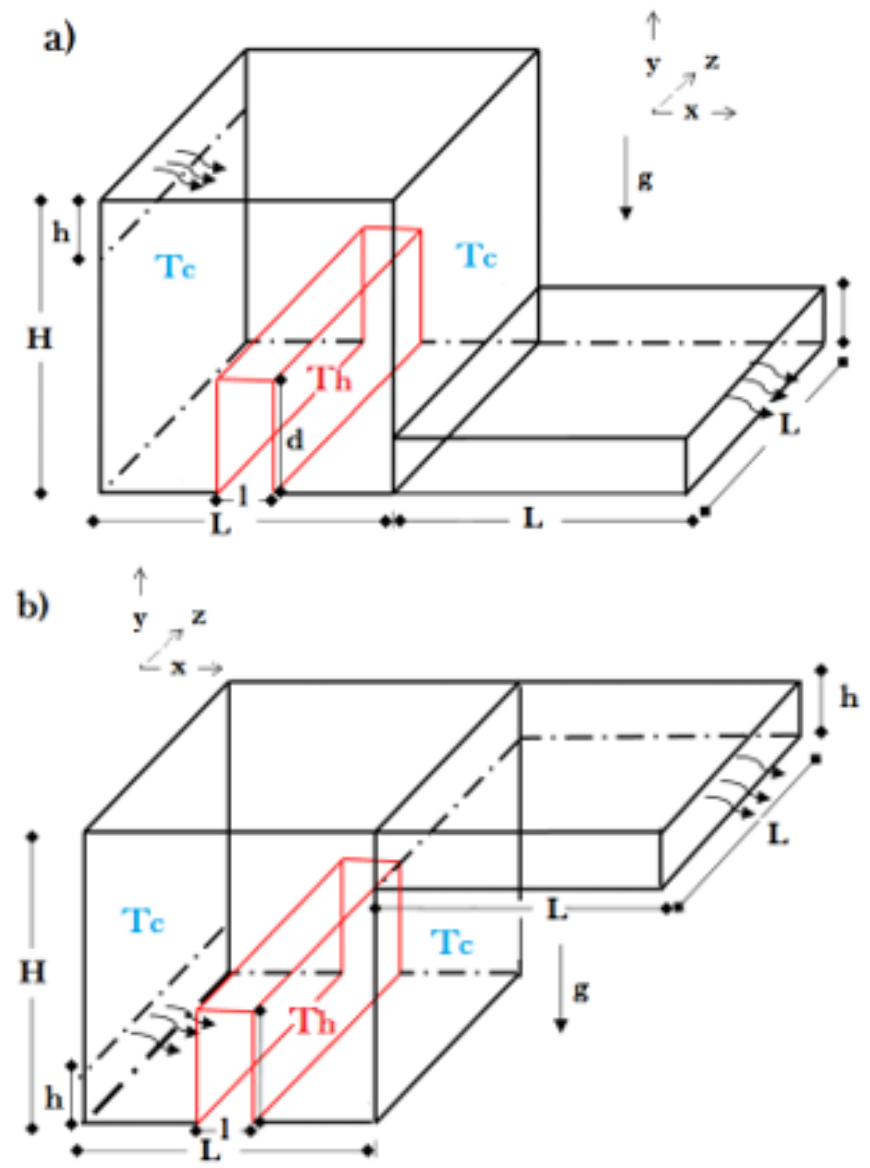

Figure 1. Studied configuration and coordinates

The cavity contains an isothermal heating block $T_{H}$ placed in the middle of the bottom wall. The internal block is rectangular, of relative length $(\mathrm{C}=\mathrm{l} / \mathrm{L}=0.2)$, height $(\mathrm{D}=\mathrm{d} / \mathrm{L}=$ $0.40)$ and a relative width $(\mathrm{L}=1)$. The vertical walls of the cavity are kept at the same temperature $T_{C}$ as the external airflow. The other four walls of the cavity are maintained adiabatic.

A channel with the same cross section and a length of $(\mathrm{L}=1)$ is placed at the opening of the left vertical wall to 
extend the cavity and makes it possible to use the developed boundary conditions for the fluid flow and heat transfer at the outlet.

The cooling fluid is considered laminar, Newtonian and incompressible with negligible viscous dissipation. All the thermo-physical properties of the fluid are assumed constant except the density, giving rise to the buoyancy forces verifying the Boussinesq approximation.

The governing equations for the 3D laminar incompressible fluid are expressed in the following dimensionless form:

$\frac{\partial U}{\partial X}+\frac{\partial V}{\partial Y}+\frac{\partial W}{\partial Z}=0$

$U \cdot \frac{\partial U}{\partial X}+V \cdot \frac{\partial U}{\partial Y}+W \cdot \frac{\partial U}{\partial Z}=-\frac{\partial P}{\partial X}+\frac{1}{R e}\left(\frac{\partial^{2} U}{\partial X^{2}}+\frac{\partial^{2} U}{\partial Y^{2}}+\frac{\partial^{2} U}{\partial Z^{2}}\right)$

$U \cdot \frac{\partial V}{\partial X}+V \cdot \frac{\partial V}{\partial Y}+W \cdot \frac{\partial V}{\partial Z}=-\frac{\partial P}{\partial Y}+\frac{1}{R e}\left(\frac{\partial^{2} V}{\partial X^{2}}+\frac{\partial^{2} V}{\partial Y^{2}}+\frac{\partial^{2} V}{\partial Z^{2}}\right)+$ $\frac{G r}{R e^{2}} \cdot \theta$

$U \cdot \frac{\partial W}{\partial X}+V \cdot \frac{\partial W}{\partial Y}+W \cdot \frac{\partial W}{\partial Z}=-\frac{\partial P}{\partial Z}+\frac{1}{R e}\left(\frac{\partial^{2} W}{\partial X^{2}}+\frac{\partial^{2} W}{\partial Y^{2}}+\frac{\partial^{2} W}{\partial Z^{2}}\right)$

$U \cdot \frac{\partial \theta}{\partial X}+V \cdot \frac{\partial \theta}{\partial Y}+W \cdot \frac{\partial \theta}{\partial Z}=\frac{1}{R e \cdot P r}\left(\frac{\partial^{2} \theta}{\partial X^{2}}+\frac{\partial^{2} \theta}{\partial Y^{2}}+\frac{\partial^{2} \theta}{\partial Z^{2}}\right)$

The non-dimensional variables are defined as follows:

$X=\frac{x}{L}, Y=\frac{y}{L}, Z=\frac{z}{L}$

$U=\frac{u}{U_{i}}, V=\frac{v}{U_{i}}, W=\frac{w}{U_{i}}, P=\frac{p-p_{0}}{\rho_{0} U_{i}{ }^{2}} \quad, \theta=\frac{T-T_{C}}{T_{H}-T_{C}}$

where $p_{0}$ and $\rho_{0}$ are respectively the reference pressure and density. $T_{H}$ is the temperature at the heated surface, $T_{C}$ the temperature at the cooled surface and $\mathrm{p}$ the pressure.

In the above equations, the parameters $\mathrm{Pr}, \mathrm{Gr}$ and $\mathrm{Re}$ denote the Prandtl number, Grashof number and the Reynold number, respectively. These parameters are defined as:

$R e=\frac{L \cdot u_{i}}{\vartheta}, G r=\frac{g \beta L^{3}\left(T_{H}-T_{C}\right)}{\vartheta^{2}}, R i=\frac{G r}{R e^{2}} \quad, \operatorname{Pr}=\frac{\vartheta}{\alpha}$

where $\beta, v$ and $\alpha$ are the thermal expansion coefficient, the

a)

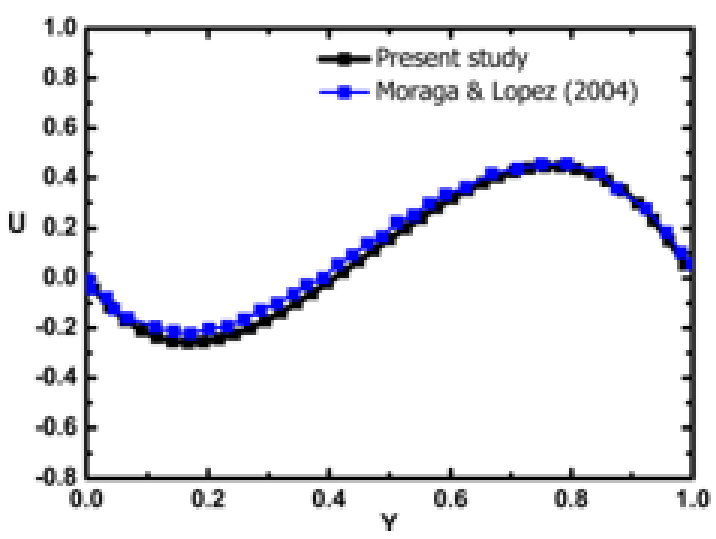

kinematic viscosity and the thermal diffusivity, respectively.

The boundary conditions, associated to the problem are:

$\checkmark \quad U=V=W=0$ on the rigid walls and on the internal heating block;

$\checkmark \quad U=1, V=W=0, \theta_{c}=0$ at the inlet;

$\checkmark \quad \theta_{H}=1$ on the isothermal heating block;

$\checkmark \quad \theta_{c}=0$ on the left and right vertical cooled walls;

$\checkmark \quad \frac{\partial \theta}{\partial \mathrm{n}}=0$ on other vertical and horizontal walls (" $\mathrm{n}$ " is the normal direction to the considered wall)

$\checkmark \quad \frac{\partial U}{\partial X}=0, \frac{\partial \theta}{\partial X}=0, V=W=0$ at the outlet.

The heat transfer is calculated on the surfaces of the heating block. Hence, the corresponding local Nusselt numbers and the average Nusselt are respectively defined by:

$N u_{\text {local }}=\frac{\partial \theta}{\partial k}$

" $k "$ is the normal direction to the heated plane

$N u_{\text {left surface }}=\frac{1}{D} \int_{0}^{D} \int_{0}^{L} N u_{\text {local }}(Y, Z) d Y d Z$
$N u_{\text {right surface }}=\frac{1}{D} \int_{0}^{D} \int_{0}^{L} N u_{\text {local }}(Y, Z) d Y d Z$
$N u_{\text {top surface }}=\frac{1}{C} \int_{\frac{L-C}{2}}^{\frac{L+C}{2}} \int_{0}^{L} N u_{\text {local }}(X, Z) d X d Z$
$N u_{\text {global }}=N u_{\text {left surface }}+N u_{\text {right surface }}+N u_{\text {top surface }}$

The incompressible Navier-Stokes and energy equations are discretized by the finite volume method developed by Patankar [27] adopting the power law scheme for the convective terms. The SIMPLEC algorithm is used to couple momentum and continuity equations. The discretized equations are iteratively solved using an Alternating Direction Implicit (ADI) scheme. The system of algebraic equations is then solved iteratively by means of the Thomas algorithm.

b)

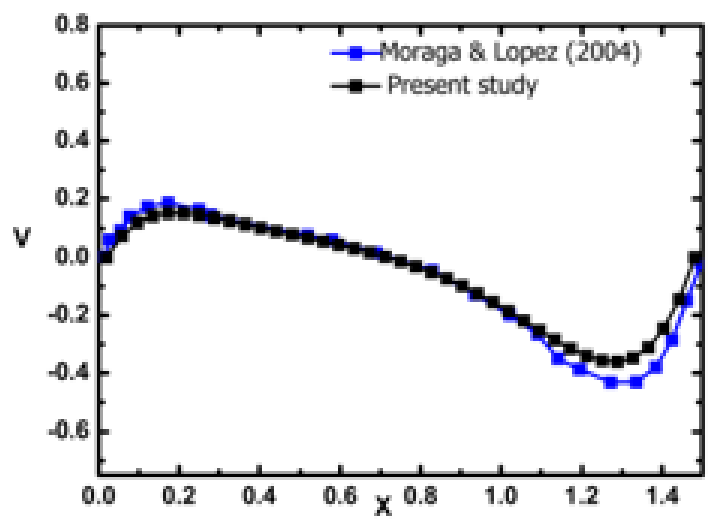

Figure. 2 a). $\mathbf{U}$ velocity component at $X=0.75, Z=0.5$ b).V velocity component at $Y=0.5, Z=0.5$ 

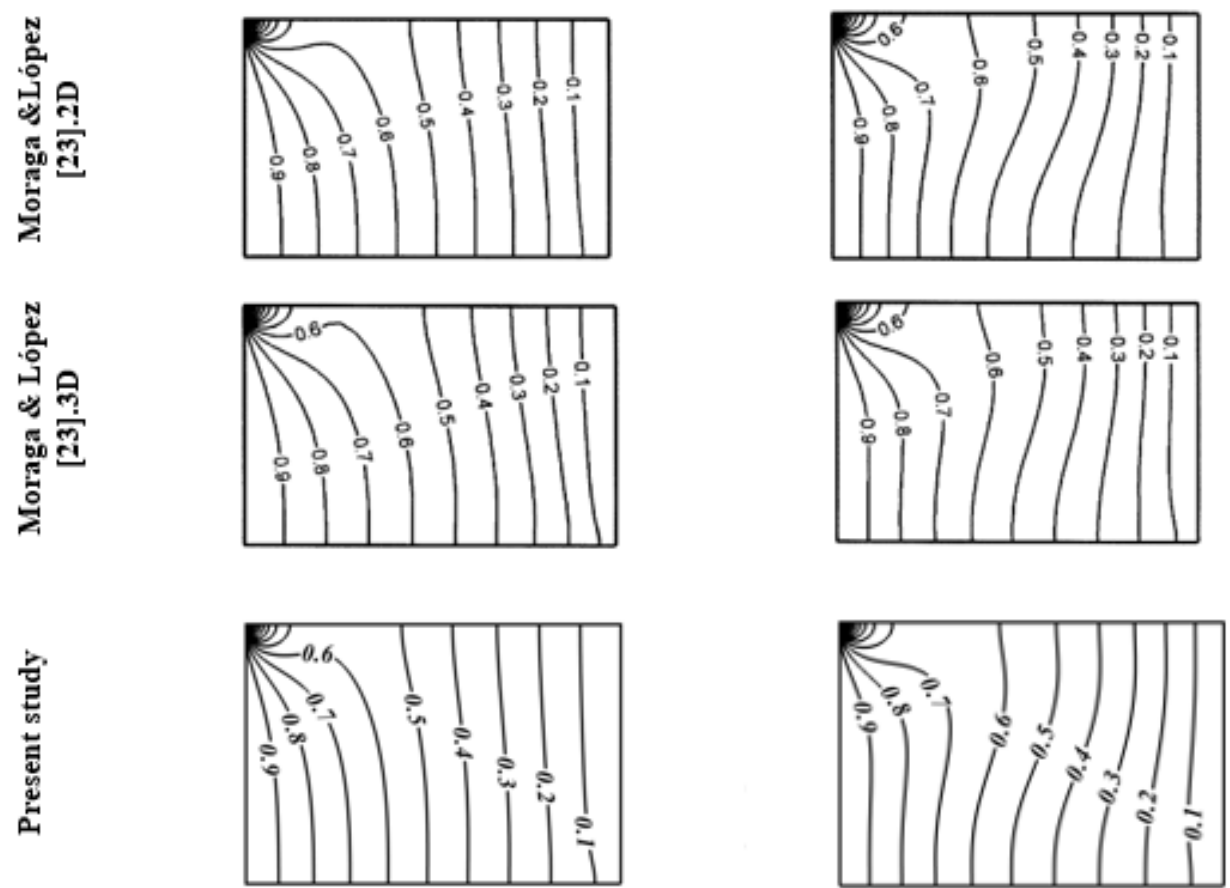

Figure 3. Comparison between the isotherms obtained at the middle plane $\mathrm{Z}=0.5$ and those of Moraga and López [23]

The convergence of the numerical code is established according to the following criterion:

$\sum_{i, j, k=1}^{\text {imax,jmax }, \operatorname{kmax}} \frac{\left|\phi_{i, j, k}^{m+1}-\phi_{i, j, k}^{m}\right|}{\left|\phi_{i, j, k}^{m}\right|} \leq 10^{-5}$

where $\phi$ represents a dependent variable $\mathrm{U}, \mathrm{V}, \mathrm{W}, \mathrm{T}$, and $\mathrm{P}$, the indices $\mathrm{i}, \mathrm{j}$, and $\mathrm{m}$ indicate the grid positions and $\mathrm{m}$ represents the iteration number

\section{CODE AND GRID SIZE VALIDATION}

The preliminary tests were conducted to check the grid independency of the solution using different uniform grid sizes. The grid $91 \times 71 \times 71$ was estimated to be appropriate for the present study since it permits a good compromise between the computational cost and the accuracy of the obtained results. In fact, the maximum deviation remains within under $1.5 \%$ when the grid was refined to $111 \times 91 \times 91$.

The obtained results are compared with the existing 2D and 3D studies by Moraga \& López [23], in terms of velocity and isotherms, for different sets of the governing parameters. (Figs. 2a-2b) show $\mathrm{U}$ and $\mathrm{V}$ velocity components at the vertical and horizontal midlines respectively, for $\mathrm{Re}=10$ and $\mathrm{Ri}=10$. Figure. 3 shows the isotherms $2 \mathrm{D}$ and $3 \mathrm{D}$ models for $\mathrm{Re}=10, \mathrm{Ri}=0.1$ and 10 at $\mathrm{Z}=0.5$. It can be seen from this comparison that there is a good agreement between the present results and those presented by Moraga \& López [23].

\section{RESULTS AND DISCUSSION}

A numerical study has been made to point out the conjugated effects of the thermal parameters on the heat transfer and fluid flow phenomena within a three- dimensional ventilated cavity with internal block heater. The results presented in this section were obtained for Richardson numbers Ri ranging between 0 and 10 and Reynolds number Re varying between 50 and 200, which correspond to a laminar regime. The relative height of the openings B and the Prandtl number are fixed respectively to $1 / 8$ and 0.71 . a)

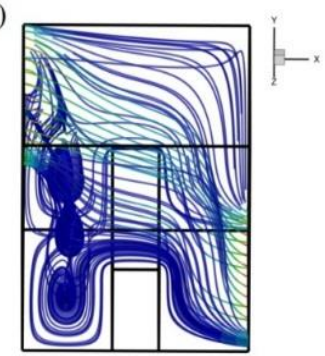

b)

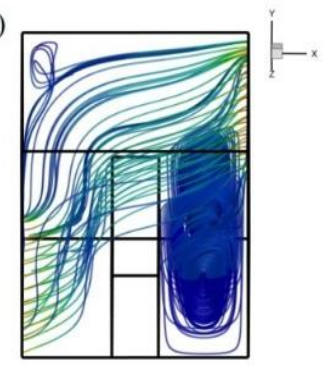

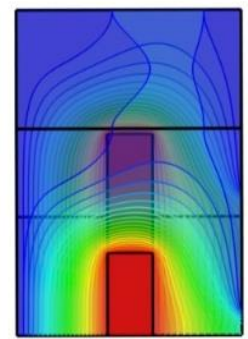

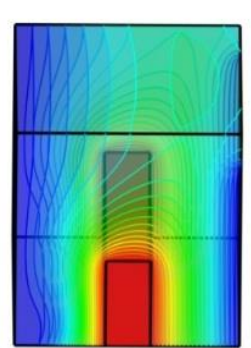

0.95 0.9 0.85
0.8 0.75 0.7 0.65 0.6 0.55 0.5 0.5 0.4 0.4
0.35 0.35
0.3
0.25 0.1
0.05
Figure 4. 3 -D streamlines and isotherm lines for $\mathrm{Re}=100$ and $\mathrm{Ri}=1$ a) $\mathrm{TB}$ configuration b) BT configuration

In order to give a comprehensive visualization of the flow and the temperature distribution within the studied configurations, streamlines (left) and isotherms (right) in 3D for the TB and BT configurations are respectively shown in (Figures. $4 \mathrm{a}-4 \mathrm{~b}$ ), for $\mathrm{Re}=100$ and $\mathrm{Ri}=10$. It is seen that the fluid motion and isotherm lines are strongly affected by the changing of inlet and outlet positions. 


\subsection{TB configuration}

At first, we considered the TB configuration where the air injection is from the top of the vertical cold wall. Hence, Figs. 5-6 are representing the flow and temperature distribution in the mid-plane of the cavity $\mathrm{XY}(\mathrm{Z}=0.5)$ then at $\mathrm{X}=0.25$, $X=0.75$ respectively. In fact, the analysis of the isotherms and streamlines in different planes $(0 \leq Z \leq 1)$ shows a perfect symmetry with respect to the plane $Z=0.5$. This is due to the geometrical symmetry and adopted thermal boundary conditions, except for the case $(\operatorname{Re}=200, \mathrm{Ri}=10)$.

For the lower Richardson and $(\mathrm{Ri}<1)$ (Fig. 5-a) and at Reynolds number $(\operatorname{Re}=50)$, the inflow is not strong enough and the open lines pattern conserves the same form and submit a slight deflection on the upper part of the block until the outlet. A small clockwise rotating vortex is located under the opened lines of the forced flow. The size of this vortex increases for moderate value of Reynolds number $(\mathrm{Re}=100)$. The corresponding isotherms are tightened around the heated isothermal block, and the temperature distribution is curved and parallel to each other in the remaining parts of the cavity, testifying of a dominant conduction heat transfer.

As the Reynolds number increases to $(\operatorname{Re}=200)$, the flow structure become intense. The size of the vortex increases until it reaches the up left side of the block, while a small counterclockwise vortex appears beneath it and another small one appears in the upper corner of the cavity. The inclined isotherms move to the left side, where the vortexes are created inside the cavity. In fact the heat diffusion provided by the isothermal block is pushed by the incoming accelerated flow from the outlet. This justifies the reduction of the cavity upper zone phenomenon, pointing out that the vigorous actions of the inertia forces are playing the main role in the flow transport.

As the Richardson number increases to $(\mathrm{Ri}=1)$, (Fig. 5-b) and for a week Reynolds number $(\mathrm{Re}=50)$, a single counterclockwise vortex is generated at the left side of the block and the closed cell under the opening almost disappears. On the other hand, the increase of the Reynolds number to ( $R e=100)$, leads to the formation of two small vortexes at the up-left and at the right parts of the block. In addition, the left side vortex is progressively growing in size. This happens when the inertia and buoyancy forces balance each other, leading to a mixed convection. A similar behavior with a small difference has been

observed in the case of the isotherm lines, compared to the pure forced convection $(\mathrm{Ri}=0)$.
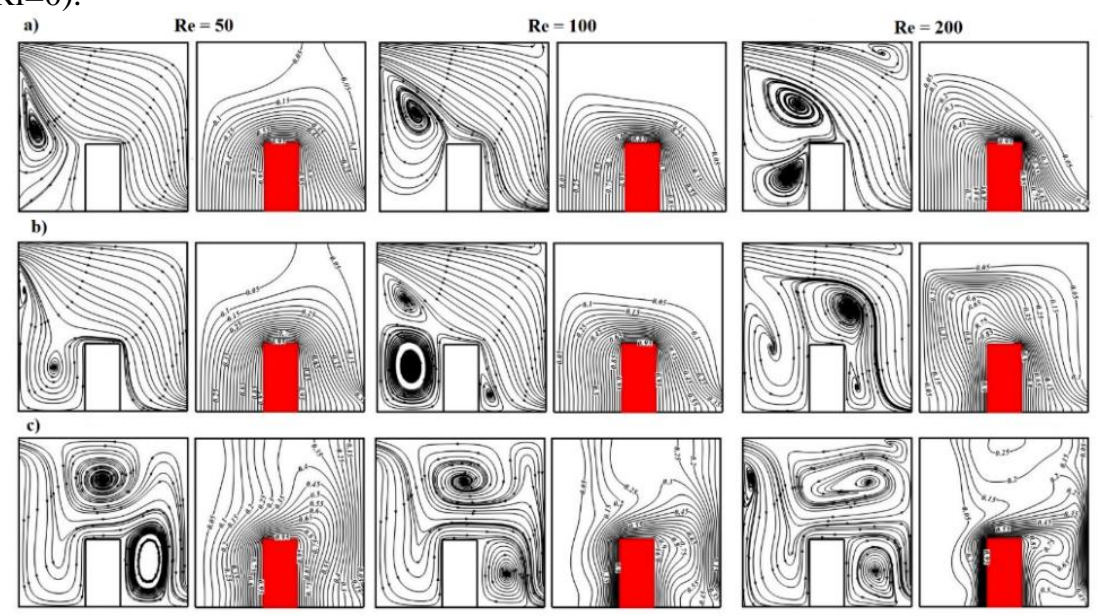

Figure 5. Streamlines (left) Isotherms (right) at $\mathrm{Z}=0.5$ for: (a) $\mathrm{Ri}=0$; (b) $\mathrm{Ri}=1 ;(\mathbf{c}) \mathrm{Ri}=10$ for various values of $\mathrm{Re}$ 

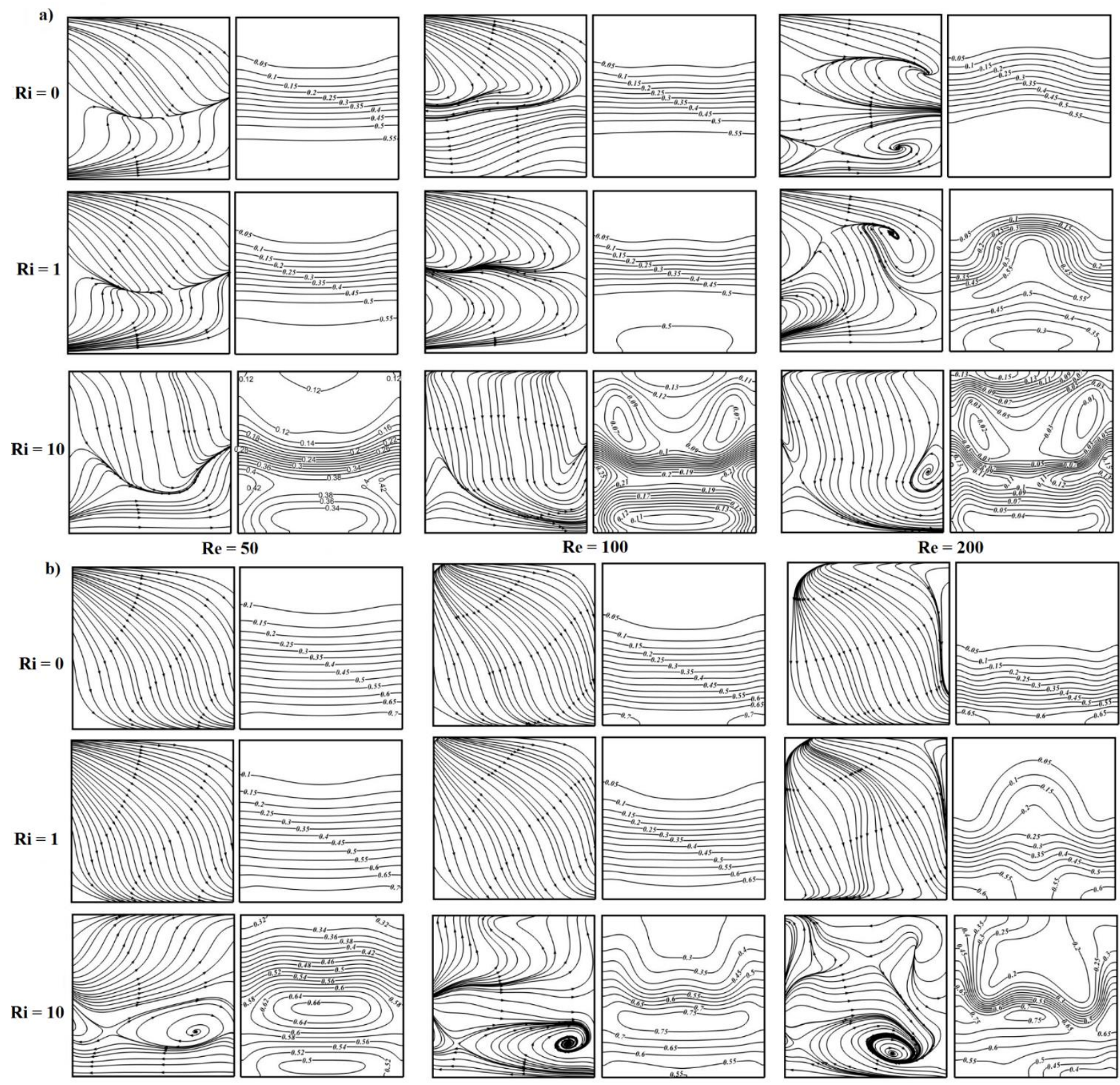

Figure 6. Streamlines (left) Isotherms (right) at $\mathrm{Z}=0.5$ and $\mathrm{Y}=0.5$ for: (a) $\mathrm{X}=0.25$; (b) $\mathrm{X}=0.75$; for various values of $\mathrm{Ri}$ and $\mathrm{Re}$

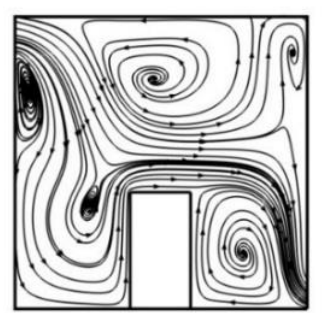

$$
\mathrm{Z}=\mathbf{0 . 1 5}
$$

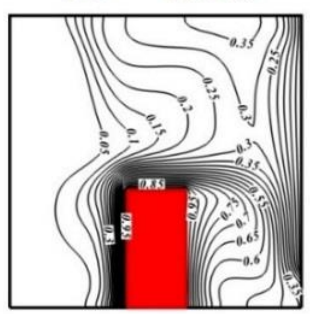

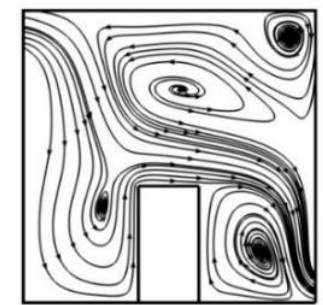
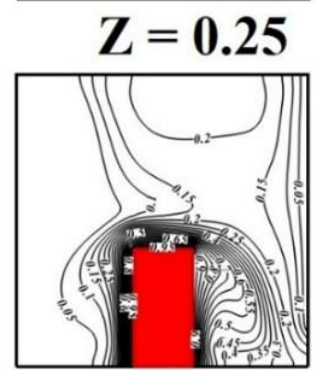
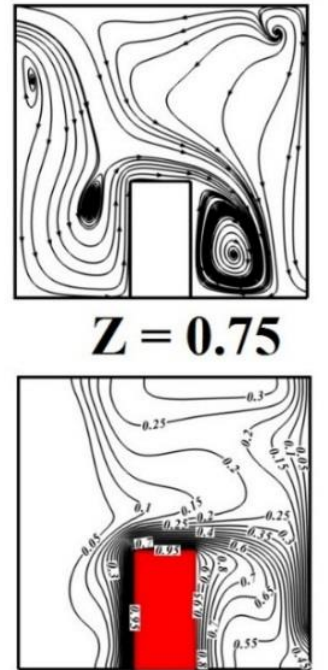

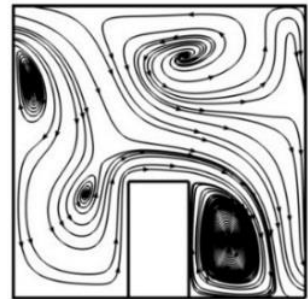

$$
\mathrm{Z}=\mathbf{0 . 8 5}
$$

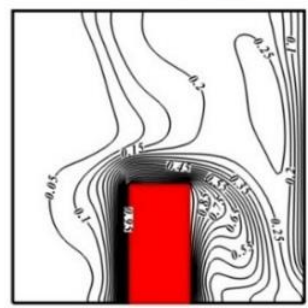

Figure 7. Streamlines, Isotherms for different $\mathrm{Z}$ plans for $\mathrm{Re}=200$ and $\mathrm{Ri}=10$ 


\subsection{BT configuration}

In order to analyze the flow structures and the thermal performance compared to the previous case, we present in Fig. 8 the streamline and isotherms at mid-plane $\mathrm{XY}(\mathrm{Z}=0.5)$ for the $\mathrm{BH}$ configuration where the air injection is from the bottom of the cold vertical wall and leaves from the top of the opposite cold wall. It should be noted that in this case the symmetry is preserved for all the considered thermal parameters.

Three modes of heat transfer, characterized by the buoyancy parameter $\mathrm{Ri}$ value, are encountered, namely forced convection, mixed convection and natural convection dominating regimes.

In the absence of the natural convection for $(\mathrm{Ri}=0)$, (Fig. 8-a), a series of computations were executed by increasing the Reynolds number from 50 to 200. At low Reynolds numbers $(\operatorname{Re}=50)$, the open lines related to the external forced flow occupies almost the whole left area of the block reaching the outlet and formed a circulating vortex rotating in the clockwise direction near the right cold wall

By increasing Reynolds to moderate value, $(\operatorname{Re}=100)$, the streamlines show the existence of two circulation zones separated by the open lines of the forced flow. The vortex cell above the external accelerated flow is then growing in size with more increase of $(\operatorname{Re}=200)$, that can be explained by the dominance of the inertia effects. The distribution of the isotherms inside the cavity shows that the lower temperatures are almost parallel to each other near the vertical cold walls. However, the temperature distribution is inclined around the heated block oriented towards the outlet. This behavior is similar to a pure conduction heat transfer. Furthermore, the cold zone increases by increasing Reynolds numbers causing a visible tightening of the isotherms at the left part of the block.

A change in the flow structure in the left upper part of the cavity is then observed. As the Richardson number increases to $\mathrm{Ri}=1$ (Fig. 8-b), the forced and natural convection assist each other, whereas, the size and the intensity of the convective cell at the right part of the bloc increase by increasing Reynolds numbers. The corresponding isotherms have similar shapes with a small difference compared to the previous case $(\mathrm{Ri}=0)$

By increasing the Richardson number to $(\mathrm{Ri}=10)$, (Fig. 8c), the internal buoyancy effect becomes important leading to the formation of two closed convective cells divided by the open lines of forced flow. This counterclockwise cell which, located above the forced flow and closer to the left vertical cold wall, increases in size and intensity by increasing $\mathrm{Re}$ numbers. The other clockwise rotating one occupies almost the whole right zone of the block. This enhancement of the flow intensity leads to more circulation of the heat from the isothermal heating block to the right cold wall until the outlet. In fact, the higher temperature gradients are dense around the heated block as shown from the analyze of the corresponding isotherms. a)

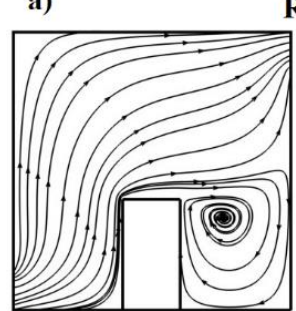

b)

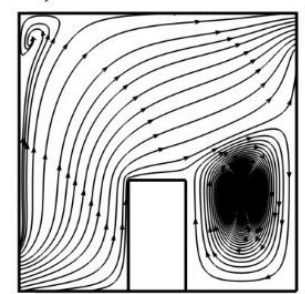

c)

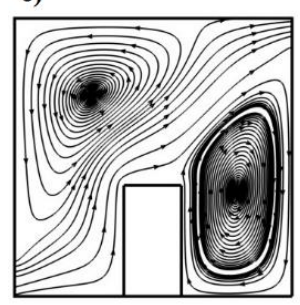

$\mathbf{R e}=\mathbf{5 0}$
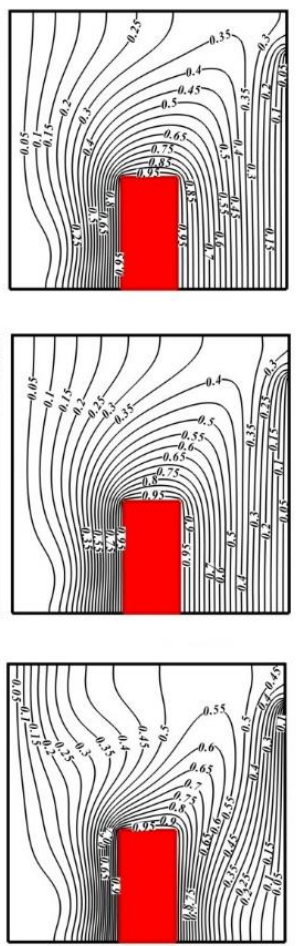

$\mathbf{R e}=\mathbf{1 0 0}$
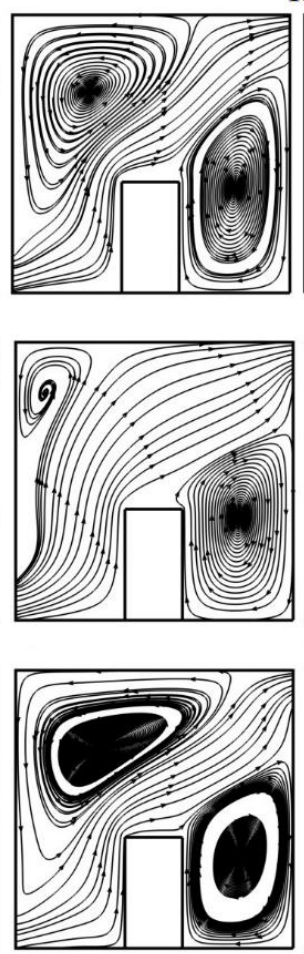
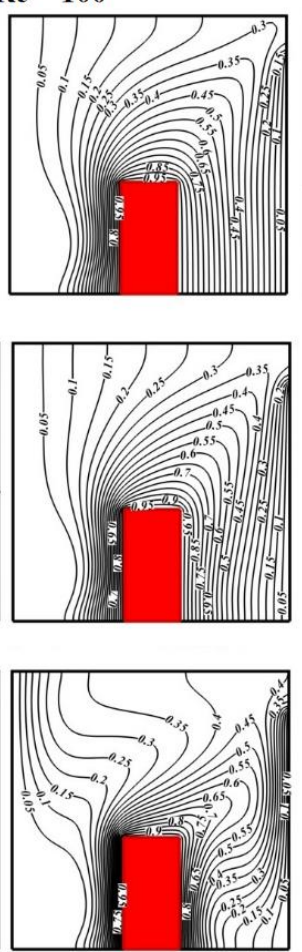

$\operatorname{Re}=\mathbf{2 0 0}$
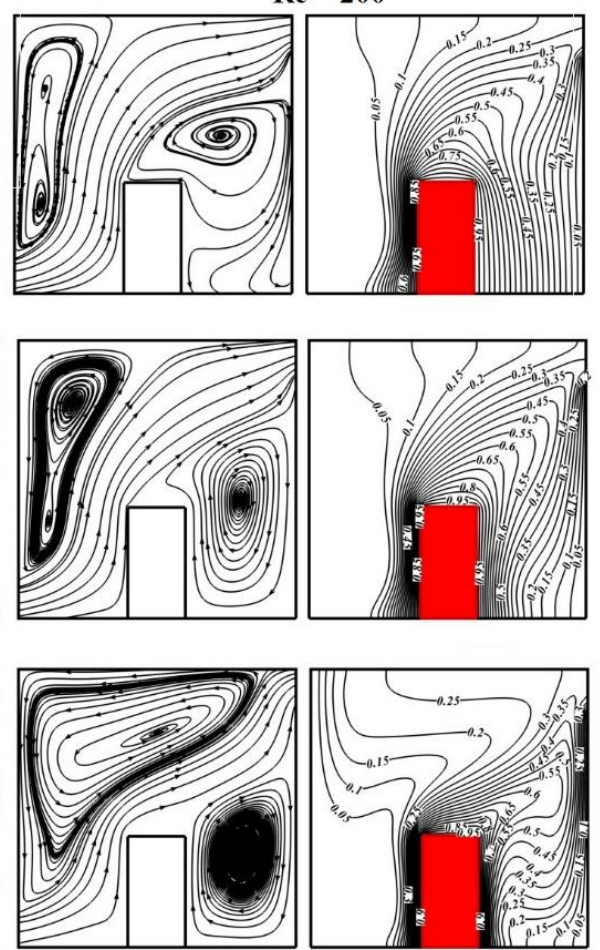

Figure 8. Streamlines (left) Isotherm lines (right) at $\mathrm{Z}=0.5$ for: (a) $\mathrm{Ri}=0 ;(\mathbf{b}) \mathrm{Ri}=1 ;(\mathbf{c}) \mathrm{Ri}=10$ for various values of $\mathrm{Ri}$

\subsection{Heat transfer enhancement}

In order to analyze the thermal performance of the studied configurations, we present the variations of the global average Nusselt numbers as function of $\mathrm{Re}$ and $\mathrm{Ri}$ values for the TB and BT competing configurations respectively in (Fig. 9-a), and (Fig. 9-b), The global Nusselt numbers calculated by double integration of local Nusselt number over the heating surfaces is given by Eq. (11). As expected the global Nusselt number increases with increasing Reynolds numbers for all considered values of Richardson numbers for both configurations. This can be explained by the increase of the external incoming flow rate, which interacts favorably with the internal heated block. 
(a)

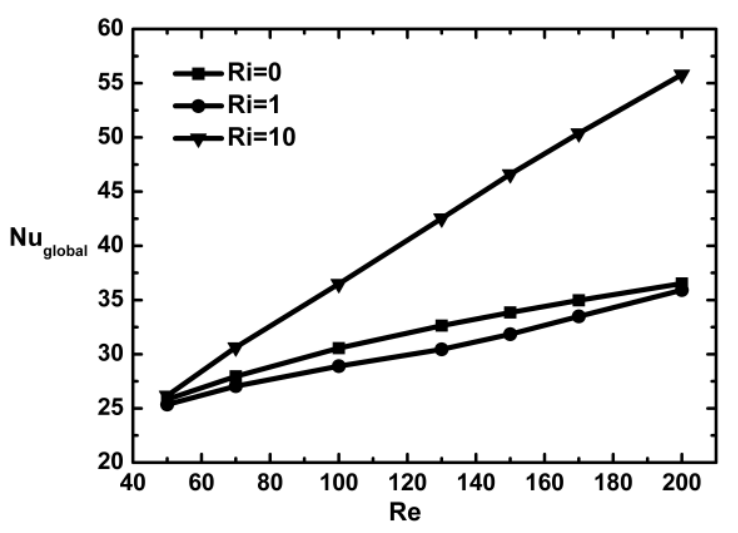

(b)

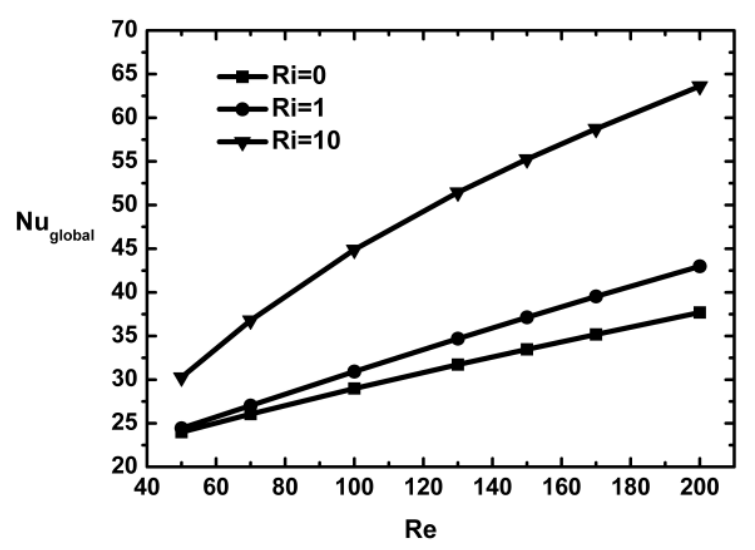

Figure 9. Variation of the global Nusselt number for (a)TB configuration and (b) BT configuration with Re for $\mathrm{Ri}=0,1,10$
However, for the TB configuration (Fig. 9-a), at lower Richardson numbers $(\mathrm{Ri}<1)$, (forced convection domain), the heat transfer rate is more important. When $(\mathrm{Ri}=1)$, (mixed convection), conduction heat transfer becomes stronger than mixed convection.

Furthermore, the increase of the Richardson number $(\mathrm{Ri}=10)$, results in the enhancement of the average Nusselt number and obviously the heat transfer, since the buoyancy effects become the dominant mode of the mixed convection transport.

The BT configuration (Fig. 9-b) conducted a higher thermal performance characterized by a monotonic increase with Ri.

It is also of great interest to examine the variation of the average Nusselt numbers along the Right, left and top surface of the heated block, which are shown in (Table 1).and (Table 2). for TB and BT configurations respectively. As we can notice from Table 1 , for $\mathrm{Ri} \leq 1$, the heat transfer rate at the top surface of the block exceeds the right and left surfaces. The external forced flow remains partially in direct contact with the top heated block what involves a continuous increase in global Nusselt numbers. It should be noted that for $(\mathrm{Ri}=0)$, the Nusselt number at the left part of the block increases for lowest $\operatorname{Re}$ then decreases when $(\operatorname{Re} \geq 100)$. At this stage, the forced convection plays a major role in heat removal. When ( $\mathrm{Ri} \geq 10$ ), most of the heat transfer takes place through the left surface of the block. Characterizing a maximum interaction between the internal heated air and the incoming accelerated flow, which leads to a better stratification of the temperature in the left region of the block. Referring to Table 2, which corresponds to the BT configuration, the heat transfer is very intense at the left surface of the block when it is compared to the right and top surfaces of the heated block. This can be explained by the direct collision of the external cold air jet on the left side of the heated block.

Table 1. Variation of Nusselt number along the heated surfaces (right, left and top) as function of Reynolds and Richardson numbers for TB configuration

\begin{tabular}{|c|c|c|c|c|c|c|c|c|c|}
\hline \multirow{3}{*}{$\mathbf{R e}$} & \multicolumn{9}{|c|}{$\mathbf{R i}$} \\
\hline & \multicolumn{3}{|c|}{0} & \multicolumn{3}{|c|}{1} & \multicolumn{3}{|c|}{10} \\
\hline & $\mathrm{Nu}_{\text {right surface }}$ & $\mathrm{Nu}_{\text {left surface }}$ & $\mathrm{Nu}_{\text {top surface }}$ & $\mathrm{Nu}_{\text {right surface }}$ & $\mathrm{Nu}_{\text {left surface }}$ & $\mathrm{Nu}_{\text {top surface }}$ & $\mathrm{Nu}_{\text {right surface }}$ & $\mathrm{Nu}_{\text {left surface }}$ & $\mathrm{Nu}_{\text {top surface }}$ \\
\hline 50 & 6.41 & 6.794 & 12.800 & 6.071 & 6.928 & 12.354 & 6.424 & 9.955 & 9.800 \\
\hline 70 & 6.815 & 6.847 & 14.289 & 6.489 & 7.083 & 13.484 & 6.740 & 12.739 & 11.159 \\
\hline 100 & 7.734 & 6.736 & 16.736 & 7.156 & 7.227 & 14.513 & 6.382 & 16.801 & 13.306 \\
\hline 150 & 9.205 & 6.396 & 18.247 & 8.195 & 8.043 & 15.607 & 8.345 & 22.041 & 16.220 \\
\hline 170 & 9.749 & 6.274 & 18.949 & 8.485 & 8.686 & 16.321 & 9.396 & 23.800 & 17.194 \\
\hline 200 & 10.499 & 6.126 & 19.894 & 8.936 & 9.709 & 17.275 & 11.053 & 26.196 & 18.549 \\
\hline
\end{tabular}

Table 2 Variation of Nusselt number along the heated surfaces (right, left and top) as function of Reynolds and Richardson numbers for BT configuration

\begin{tabular}{|c|c|c|c|c|c|c|c|c|c|}
\hline \multirow[b]{3}{*}{$\mathbf{R e}$} & \multicolumn{8}{|c|}{$\mathbf{R i}$} & \\
\hline & \multicolumn{3}{|c|}{0} & \multicolumn{3}{|c|}{1} & \multicolumn{3}{|c|}{10} \\
\hline & $\mathrm{Nu}_{\text {right surface }}$ & $\mathrm{Nu}_{\text {left surface }}$ & $\mathrm{Nu}_{\text {top surface }}$ & $\mathrm{Nu}_{\text {right surface }}$ & $\mathrm{Nu}_{\text {left surface }}$ & $\mathrm{Nu}_{\text {top surface }}$ & $\mathrm{Nu}_{\text {right surface }}$ & $\mathrm{Nu}_{\text {left surface }}$ & $\mathrm{Nu}_{\text {top surface }}$ \\
\hline 50 & 5.755 & 10.225 & 8.004 & 5.944 & 10.587 & 7.901 & 8.520 & 13.388 & 8.357 \\
\hline 70 & 5.761 & 11.946 & 8.342 & 6.163 & 12.565 & 8.361 & 10.512 & 16.523 & 9.761 \\
\hline 100 & 5.836 & 14.312 & 8.842 & 6.733 & 15.275 & 8.919 & 13.093 & 20.358 & 12.658 \\
\hline 150 & 6.105 & 17.854 & 9.511 & 8.291 & 19.204 & 9.653 & 16.541 & 25.438 & 13.279 \\
\hline 170 & 6.263 & 19.152 & 9.756 & 9.071 & 20.605 & 9.855 & 17.759 & 27.183 & 13.795 \\
\hline 200 & 6.544 & 20.983 & 10.114 & 10.318 & 22.557 & 10.161 & 19.643 & 29.558 & 14.418 \\
\hline
\end{tabular}




\section{CONCLUSION}

A numerical study has been carried out in the case of laminar three-dimensional mixed convection flow with an isothermal block heater in a two configurations with different inlet-outlet locations.

The main finding of the present study can be summarized as follows:

$\checkmark$ The flow structures and temperature distribution are considerably affected by the interaction between the inertia and the buoyancy forces

$\checkmark \quad$ In the case of TB configuration the symmetry is not preserved with respect to the plane $\mathrm{Z}=0.5$ when $\mathrm{Re}=200$ and $\mathrm{Ri}=10$

$\checkmark \quad$ For fixed Richardson number, the total Nusselt number increases by increasing Re numbers

$\checkmark \quad$ The forced convection was found to be favorable in heat removal for TB configuration when $\mathrm{Ri}<10$

$\checkmark$ The heat transfer rate was found to be higher when the injecting air through the bottom of the left vertical wall (BT configuration) precisely at the left surface of the block when it is compared to the right and top surfaces, and it increase by increasing $\mathrm{Ri}$.

\section{REFERENCES}

[1] Papanicolaou E, Jaluria Y. (1990). Mixed convection from an isolated heat source in a rectangular enclosure. Numer Heat Transfer, Part A 18(4): 427-461. https://doi.org/10.1080/10407789008944802

[2] Papanicolaou E, Jaluria Y. (1993). Mixed convection from a localized heat source in a cavity with conducting walls: A numerical study. NumerHeat Transfer, Part A 23(4):

463-484. https://doi.org/10.1080/10407789308913683

[3] Hsu TH, Hsu PT, How SP. (1997). Mixedconvection in a partially divided rectangular enclosure. Numer Heat Transfer, Part A 31(6): 655-683. https://doi.org/10.1080/10407789708914058

[4] Manca O, Nardini S, Khanafer K, Vafai K. (2003). Effect of heated wall position on mixed convection in a channel with an open cavity. Numer Heat Transfer, Part A 43(3): 259-282. https://doi.org/10.1080/10407780307310

[5] Manca O, Nardini S, Vafai K. (2006). Experimental investigation of mixed convection in a channel with an open cavity. Experimental Heat Transfer 19(1): 53-68. https://doi.org/10.1080/08916150500318380

[6] Raji A, Hasnaoui M. (1998a). Mixed convection heat transfer in a rectangular cavity ventilated and heated from the side. Numer Heat Transfer, Part A 33(5): 533548. https://doi.org/10.1080/10407789808913953

[7] Raji A, Hasnaoui M. (1998b). Corrélations en convection mixte dans des cavités ventilées. Revue Générale de Thermique 37(10): 874-884. https://doi.org/10.1016/S0035-3159(98)80012-3

[8] Raji A, Hasnaoui M. (2000). Mixed convection heat transfer in ventilated cavities with opposing and assisting flows. Eng Comput: Int J Computer-Aided Eng Software 17(7): 556-572. https://doi.org/10.1108/02644400010339770

[9] Raji A, Hasnaoui M. (2001). Combined mixed convection and radiation in ventilated cavities. Eng
Comput: Int J Computer-Aided Eng Software 18(7): 922-949. https://doi.org/10.1108/EUM0000000006212

[10] Bahlaoui A, Raji A, Hasnaoui M, Ouardi C, Makayssi T. (2011). Height partition effect on combined mixed convection and surface radiation in a vented rectangular cavity. Journal of Applied Fluid Mechanics 4(1): 89-96.

[11] Bahlaoui A, Raji A, Hasnaoui M. (2004). Coupling between mixed convection and radiation in an inclined channel locally heated. J Mech Eng 55: 45-57.

[12] Bahlaoui A, Raji A, Hasnaoui M, Naïmi M, Makayssi T, Lamsaadi M. (2009). Mixed convection cooling combined with surface radiation in a partitioned rectangular cavity. Energy Conversion and Management 50(3): 626-635. https://doi.org/10.1016/j.enconman.2008.10.001

[13] Saha S, Saha G, Ali M, Quamrul Islam M. (2006). Combined free and forced convection inside a twodimensional multiple ventilated rectangular enclosure. ARPN J Eng Appl Sciences 3(1): 23-35.

[14] Messaoud H, Meziani B, Sadaoui D. (2017). Numerical study of mixed convection and flow pattern in various acrossshape concave enclosure. International Journal of Heat and Technology 35(3): 567-575. https://doi.org/10.18280/ijht.350313

[15] OMRI A, NASRALLAH SB. (1999). Control volume finite element numerical simulation of mixed convection in an air-cooled cavity. Numer Heat Transfer, Part A 36(6): 615-637. https://doi.org/10.1080/104077899274606

[16] Singh S, Sharif MAR. (2003). Mixed convective cooling of a rectangular cavity with inlet and exit openings on differentially heated side walls. Numer Heat Transfer, Part A 44(3): 233-253. https://doi.org/10.1080/716100509

[17] Rahman MM, Parvin S, Rahim NA, Islam MR, Saidur R, Hasanuzzaman M. (2012). Effects of Reynolds and Prandtl number on mixed convection in a ventilated cavity with a heat-generating solid circular block. Applied Mathematical Modelling 36(5): 2056-2066. https://doi.org/10.1016/j.apm.2011.08.014

[18] Gupta SK, Chatterjee D, Mondal B. (2015). Investigation of mixed convection in a ventilated cavity in the presence of a heat conducting circular cylinder. Numer Heat Transfer, Part A 67(1): 52-74. https://doi.org/10.1080/10407782.2014.916113

[19] Bhoite MT, Narasimham GSVL, Krishna Murthy MV. (2005). Mixed convection in a shallow enclosure with a series of heat generating components. Int $\mathrm{J}$ Thermal Sciences 44(2): 121-153. https://doi.org/10.1016/j.ijthermalsci.2004.07.003

[20] Rahman MM, Alim MA, Saha S, Chowdhury MK. (2009). Effect of the presence of a heat conducting horizontal square block on mixed convection inside a vented square cavity. Nonlinear Analysis: Modelling and Control 14(4): 531-548.

[21] Shuja SZ, Yilbas BS, Iqbal MO. (2000). Mixed convection in a square cavity due to heat generating rectangular body. International Journal of Numerical Methods for Heat \& Fluid Flow 10(8): 824-841. https://doi.org/10.1108/09615530010359120

[22] Stiriba Y, Grau FX, Ferré JA, Vernet A. (2010). A numerical study of three-dimensional laminar mixed convection past an open cavity. International Journal of Heat and Mass Transfer 53(21): 4797-4808. 
https://doi.org/10.1016/j.ijheatmasstransfer.2010.06.012

[23] Moraga NO, Lopez SE. (2004). Numerical simulation of three-dimensional mixed convection in an air-cooled cavity. Numerical Heat Transfer, Part A: Applications 45(8): 811-824. https://doi.org/10.1080/10407780490250409

[24] Doghmi H, Abourida B, Belarche H, Sannad M, Ouzaouit M. (2017). Effect of the inlet opening on mixed convection inside a three dimensional ventilated cavity. Thermal Science International Scientific Journal. https://doi.org/10.2298/TSCI170126121D

[25] Kanna PR, Anbumalar V, Krishnakumar M, Ramakrishnan A, Pushparaj SA, Kumar AS. (2014) Numerical investigation of mixed convection heat transfer from block mounted on a cavity. Arabian Journal for Science and Engineering 39(12): 9187-9204. https://doi.org/10.1007/s13369-014-1422-y

[26] Fontana É, Capeletto CA, da Silva A, Mariani VC. (2015). Numerical analysis of mixed convection in partially open cavities heated from below. International Journal of Heat and Mass Transfer 81: 829-845. https://doi.org/10.1016/j.ijheatmasstransfer.2014.11.011

[27] Patankar S. (1980).Numerical heat transfer and fluid flow. CRC Press.

\section{NOMENCLATURE}

\section{B}

C

D

g

$\mathrm{Gr}$ relative height of the openings, $(\mathrm{h} / \mathrm{L})$ relative length of the isothermal block, relative height of the isothermal block, acceleration due to gravity, $\left(\mathrm{m} / \mathrm{s}^{2}\right)$ Grashof number
$\operatorname{Re}$

$\mathrm{Ri}$

$\mathrm{u}, \mathrm{v}, \mathrm{w}$

$\mathrm{U}, \mathrm{V}, \mathrm{W}$

$\mathrm{x}, \mathrm{y}, \mathrm{z}$

X,Y,Z

\section{Greek symbols}

$\alpha$

$\theta$

$\beta$

v

$\rho$

c

$\mathrm{h}$

\section{Subscripts}

$\begin{array}{ll}\mathrm{i} ; \mathrm{j} ; \mathrm{k} & \text { node position } \\ \mathrm{i} & \text { inlet } \\ \mathrm{m} & \text { iteration number }\end{array}$
Nusselt number Prandtl number density, $\left(\mathrm{kg} / \mathrm{m}^{3}\right)$ cold hot height of the openings, height of the cavity, width of the cavity, length of the cavity, dimensionless pressure Reynolds number Richardson number dimensional velocities, $(\mathrm{m} / \mathrm{s})$ dimensionless velocity components dimensional coordinates, $(\mathrm{m})$ dimensionless cartesian coordinates

thermal diffusivity, $\left(\mathrm{m}^{2} / \mathrm{s}\right)$ non-dimensional temperature volumetric thermal expansion coefficient,(1 / K) kinematic viscosity, $\left(\mathrm{m}^{2} / \mathrm{s}\right)$ 